MCKeRRELL, H. 1972. On the origins of British faience beads and some aspects of the WessexMycenae relationship, PPS, xxxvir, 286-301.

NEWTON, R. G. and C. RENFREW. I970. British faience beads reconsidered, Antiquity, XLIV, I99-206.

PIGGOTT, s. 1938. The early bronze age in Wessex, $P P S$, IV, 52-106.

RENFREW, C. I968. Wessex without Mycenae, Annual of the British School of Archaeology at Athens, LXIII, $277-85$.

r 972 a. Beyond a subsistence economy: the evolution of social organization in prehistoric Europe, in (ed). C. Moore, The reconstruction of complex societies, International Symposium held by the Cambridge Seminar, Cambridge, Mass. 1972b. The emergence of civilization: the Cyclades and the Aegean in the third millennium $B C$ (London).

1973. Monuments, mobilization and social organization in neolithic Wessex, in (ed.) C. Renfrew, The explanation of culture change: models in prehistory (London).

SELKIRK, A. 1972. Wessex with Mycenae, Current Archaeology, 32, 225.

SHERRATT, A. 1972. Socio-economic and demographic models for the neolithic and bronze ages of Europe, in (ed.) D. L. Clarke, Models in archaeology (London), 477-542.

\title{
The Srivijayan civilization in Southern Thailand
}

Fanice Stargardt is a Fellow of Lucy Cavendish Collegiate Society and also Evans Fellow in South East Asian Archaeology at the University of Cambridge. In this note, she sets out some of the basic features of the economy of the Srivijayan civilization of Southern Thailand. We suggested that she append a further note (p.228) on progress made to date, in tests to identify the technology used in the Srivijayan ceramic tradition.

Until now, the Srivijayan tradition in Thailand was associated only with the admirable bronzes, centred in the South, but found over a wide area. Similarly, the major series of PreAngkorian Khmer Visnus from peninsular Thailand have been isolated by time from their original cultural environment. Scholars of South East Asian civilization are aware that major images such as the Srivijayan Avalokitesvaras and the Khmer Visnus would have been fashioned originally as the focal point of a monument. No Pre-Angkorian Khmer monuments or ruins have yet been found in Southern Thailand and only one Srivijayan monumentWat Boromdhatu, Chaiya-has survived intact, while Wat Chedi Ngam and Wat Sii Yang (FIG. I) contain a Srivijayan core and ruined pediment respectively. In the summer of 1971 , a Cambridge expedition identified a further seven ruined monumental sites of the Srivijayan period at Kok Tong (FIG. I).

The size and quality of the statues themselves, to which some critical attention has already been devoted (Dupont, r941 and 1955; O'Connor, I 966 and 1972; Diskul, I97 I), suggest that their original monumental context was a developed and prosperous one. The Cambridge South East Asian archaeological expedition has been working in peninsular Thailand since 1970 and the evidence it has uncovered gives us some insight for the first time into the economic, as well as the monumental, aspects of southern civilization. In this note are presented the concise results of a series of excavations relating to the economic bases of Srivijayan civilization.

\section{MODIFICATIONS IN THE ENVIRONMENT}

Southern Thailand possesses the largest body of inland waters in South East Asia (FIG. I) and this vast lake system is separated from the Gulf of Thailand by a long flat strip of land called the Satingpra Peninsula. This strip is part of a continuing process of beach build-up which, as the map shows, is still producing sand, clay and mud banks in the coastal waters. It varies between 5 and $12 \mathrm{~km}$. in width and its greatest elevation is $3-4 \mathrm{~m}$. until it terminates in a single mountain on its southern tip. Upon a deep basic stratum of grey clay there are successive layers of dune sand along the coastal perimeter, while inland, there are areas where the grey clay is overlaid by red-brown and mid-brown clay and some humus.

The Satingpra Peninsula presents most of the defensive features of an island and offers ths additional advantage of sheltered, inland waters for easy access to the isthmian hinterland. On the other hand, its soil was originally poor and it lacked natural watercourses and ponds. These 
deficiencies presented considerable barriers to the establishment there of an urban settlement (Old Songkhla), supported by efficient agriculture, transport and communications and active in manufacture and foreign trade over an extensive area in the first half of the Srivijayan period, and possibly earlier. The archaeological evidence shows that hydraulic skills played a fundamental role in control and improvement of the environment.

All of Southern Thailand has a heavy and prolonged rainy season; on the Satingpra Peninsula the problem was to retain water and exploit it for agriculture and transport, since the rains would have made the clay surface impassable. The problem of water retention was solved by the creation of some two hundred water tanks (noted, but not charted, by the Fine Arts Department, Region No, 9, Songkhla), which were dug into the clay stratum with an average size of $20 \times 30 \mathrm{~m}$. These provided water for households and animals and served agriculture, too, as seedling beds for young rice plants to gain their first growth at the end of the dry season on the residual moisture in the base of the tanks. These methods probably preserved the tanks-many of which still function todayas well as fostering agricultural efficiency (Stargardt, 1973a).

Transport, communications and trade were served by the construction of a system of canals capable of carrying sea-going ships to centres up and down the Satingpra Peninsula as well as introducing them to the natural waterways of lake and river with which the canals were skilfully integrated. The work carried out by the Cambridge expedition to trace this ancient system is by no means complete; the results to date show a hydraulic network which served a core land area of $804 \mathrm{sq} . \mathrm{km}$. and, through the direct links to lakes and rivers, served a total land area of more than double that extent. An analysis of the technology of this hydraulic system and an examination of the trade pottery and stoneware found in it have been given elsewhere (Stargardt, I973a, figs. $3^{-5}$ and roI5). The implications of that evidence concern us here, although space will not permit its repetition: the construction methods and concepts resemble those of early hydraulic achievements across the Gulf of Thailand, at Funan, between the first and sixth centuries of the modern era, whereas the Srivijayan civilization of West Indonesia was not renowned for this type of undertaking. The character of the hydraulic system, together with the preponderance of Khmer wares among the trade pottery and of Mon/Khmer small finds at Kok Tong, should be considered alongside the Pre-Angkorian Khmer statues mentioned at the beginning of this paper. They collectively remind us of the strong Khmer influence on peninsular Thailand, beginning during the Funan period, surviving the fall of Funan itself and by no means obliterated by the imposition of Srivijayan suzerainty in the early eighth century. The Satingpra hydraulic system may have derived, in time and character, from the Pre-Srivijayan Khmer period of the isthmus and been extended on the same lines during the Srivijayan period. Other trade wares found in the system include Chinese celadons, beads associated with South Indian and Ceylonese ports, West Asian glass. These convey the extent of the trading interests which crossed here.

The canals may have served yet another purpose in the struggle to control and improve the environment. The stratification exposed at two sites, Kok Moh and Kok Tong (FIG. I), suggest an improvement in the terrain coinciding with occupancy during the Srivijayan period (Stargardt, 1973b, figs. 3-6). At Kok Moh the basic stratum of grey clay was overlaid, first by sands, but then by more arable types of red and brown clays as well as humus. The agencies which effected this amelioration were undoubtedly partly natural-deposits of the seasonal floods and winds. Among the prolific deposits of the ceramic production at Kok Moh, there is, however, plenty of evidence that local firing clays were supplemented by imported clays of a variety of types. The efforts of the discriminating potters of Kok Moh to enrich and diversify their clay supply may well have been accompanied by cumulative work to convey more arable, clayey soils from the western side of the lake system and distribute 
these over the developing network of dyked and levelled rice fields. Both the particular needs of the ceramic industry and the wider needs of agriculture would have been served by the capacity of water transport to move heavy, bulky and sometimes fragile loads.

\section{CERAMIC TECHNOLOGY AND TRADE}

At Kok Moh approximately 16,000 ceramic specimens were excavated from I 6 levels of the site. Among them, 23 distinct categories of wares were represented embracing great variations in the production repertoire of this site. Prior to the excavations at this site by the Cambridge Expedition in 1971 and 1972, no ceramic tradition was associated with the Srivijayan civilization in Thailand. The prolific nature of this site and the fact that the trench exposed undisturbed parts of the firing floors at depths of $30-40 \mathrm{~cm}$. and again successively between $7^{\circ}$ and $106 \mathrm{~cm}$. have given us access to a mass of evidence about the finished products as well as the means by which they were produced. All Kok Moh wares were unglazed earthenwares but within that common medium, enormous variations in production were achieved. Wares ranged in type from fine texture, flagons with a cross-section of $2 \mathrm{~mm}$. only, some with spouts (FIG. $2 a, b$ ), and some without (FIG. 2c); to medium texture votive wares with cross-section of $7^{-12}$ mm. (FIG. $2 d$ ) and medium texture incised wares (FIGS. $3^{a}, b$, c); and heavy texture water pots, cross-section i 5-23 mm., ovens and architectural units as well as moulds (see Stargardt, I 972 and $1973 \mathrm{~b}$, fig. 17). Four basic colour groups were present at the site: slag, grey, red and yellow and the accompanying graphs (FIG. $4 a-d$ ) show variations in deposits at levels from o-r $60 \mathrm{~cm}$, by colours. Within each basic colour category, the production was diversified in the way outlined above. The greatest measure of diversification of wares was encountered in the lowest levels of the site. It was here also that the fine texture wares made their strongest showing in the overall production and it was here that typologically significant, though statistically unimportant, rare finds such as fine cream, black and half-slip wares occurred as well as the only potters' pestle to be found in Thailand outside the extreme North-East (see Stargardt, I973a, table $3^{b}$ and $1973^{b}$, table $4 b$ for graphic representations of total diversification of production at Koh Moh, by levels). The fine texture flagons have a high curvature of the bowl, a slender throat and a thin fluted collar. These features, coupled with the normal fragility of thin, unglazed earthenwares, suggest that these vessels were not intended for domestic use but as votive wares or containers in the luxury trade in oils and powdered gums which passed across the isthmus. In general, the production level and type indicated by the deposits suggests a specialized industry manufacturing for an external cash market, not a local village pottery. Klong $O$, the canal which passed the site, gave access to both the Gulf and the lakes and with them, to wider markets. The developed aesthetic sense and skilful modelling and moulding which the fine and medium texture pottery reveals are strangely at variance with the technology of the kilns in which they were fired. Firing was done on an open hearth in which an attempt was made to retain heat by means of heaped earth on three sides of the hearths (Stargardt, 1973 b, figs. 3-6). In the case of the fine wares, surprisingly high temperatures were reached by this means, at times up to II $75^{\circ} \mathrm{C}$, according to thermodifferential tests which I am carrying out in Cambridge. Yet deposits also show the effects of temperature variations within a single firing and suggest a high, overall failure rate. This was to remain a feature of Thai kilns even after the adoption of a Chinese-based kiln technology during the third reign of the Sukhotai kingdom in the North.

The blank which previously existed around the economic activities of Srivijayan societies in Southern Thailand is now beginning to be filled in. As the material evidence is recovered and appraised, it clarifies some problems such as how the Satingpra Peninsula achieved the economic base to support a monumental civilization, and with the clarification comes evidence to suggest that much was gained during the pre-Srivijayan period of civilization there which was to remain an active force during the Srivijayan period proper. 


\section{ANTIQUITY}

Appendix: The fabrication techniques of the Kok Moh fine textured, spouted wares

The cross-section measurements of the fine textured wares posed questions to us from the time that we first encountered them in the excavation site. Although the base walls frequently attain a cross-section thickness of 3-4 $\mathrm{mm}$., the typical cross-section thickness of the walls at most curved surface of the bowls is $2 \mathrm{~mm}$. The paste is extremely fine and smooth, free from grit or other tempering, and the first question that presented itself was how the potters achieved such fine vessels. The second question was that the strong presence of these fine wares in the lower levels of the kiln site suggested a high failure rate-which was to be expectedbut sherds showed that this failure rate did not result from the most obvious cause, namely, inward collapse, but rather from shattering during or after firing.

Although the external surface of these vessels presents in cross-section a light and fine striation profile, a careful examination of the internal surface showed features that did not relate to wheel-forming alone. The expertise of $\mathrm{Mr}$ Alan Spencer Green, the potter, was invaluable in reconstructing the stages of formation consistent with the marks on the inner surfaces of these vessels.

In the first stage, the basis bowl of the fine textured flagons was formed by hand over a spherical form, which may have been made of wood. This process produced the curiously tamped surface of the interior of the vessels. Striation marks are very wide-spaced and not continous around the inner surface of the bowl and would be consistent with cleaning at a later stage in the fabrication. In the course of forming, the clay would be stretched downwards over the sides of the form and the tendency was for the clay at the top to become thinner than elsewhere. As this area was to become the base of the vessel when removed from the form and righted, the deficiency was corrected by adding a small lump of clay to the inner surface, and turning the vessel slowly on the wheel while the potter's finger pressed the clay down. This process left a characteristic circular indentation of smooth clay around a small mound of rough clay at the centre of the base. To check that enough clay had been added, the base was pricked, presumably with a sliver of bamboo, in such a way as to stop just sort of the exterior surface. Many base fragments have been found which have a single hole, clearly made while the clay was wet, from the way it rises around the aperture, and which does not break the outer surface of the base. This part of the vessel was then left to dry for a short time and so to gain in hardness. Meanwhile the upper part of the bowl was also formed over the spherical form and left to harden for a short time.

The two bowl-parts were joined, on the slowly rotating wheel, at the shoulders, and the slightly hardened clay of the upper part was pulled up by the potter to form the long throat so characteristic of these wares. On the inner surface, traces of the joint line are to be seen at the shoulders and the work of the potter in drawing up partly hardened clay produced sharply defined folds on the inner surface of the clay as it enters the throat of all flagons. The throat, fluted collar and spout were all wheelformed, although many spouts show the marks of meticulous hand scraping on the outer surface and/or decoration with fine instruments after the wheel.

In contrast to the high standards of craftsmanship revealed in the fabrication of the flagons, the conditions of firing were such that little control over temperature could be maintained and, for the same type of paste and style, the thermodifferential tests have now shown that widely differing levels of heat were reached in their original firing. For the creamy-white wares with a high kaolin content, readings range from a maximum of $1200^{\circ} \mathrm{C}$ to a minimum, to date, of less than $500{ }^{\circ} \mathrm{C}$. The consequences of this variability are also to be seen in the very different degree of hardness attained by these specimens.

Acknowledgements. The work outlined here was made possible by grants from the British Academy, the Evans and Crowther-Beynon Funds of the University of Cambridge and The Wenner-Gren Foundation. The author is indebted to Mr Alan Spencer Green for his expert advice on pottery formation and to Mrs Eileen Aldworth of Lucy Cavendish Collegiate Society, for drawing the graphs.

DISKUL, s. 1971. Art in Thailand, a brief history (Bangkok), 2nd ed.

DUPONT, P. I94I. Viśnus mitrés de l'Indochine occidentale, Bulletin de l'école française d'extrême orient, XLI, 233-54.

1955. La statuaire préangkorienne (Ascona). 
o'CONNOR, S. I 966. Satingpra: an expanded chronology, Fournal of the Malaysian Branch of the Royal Asiatic Society, xxxix, 137-44.

1972. Hindu gods of peninsular Siam (Ascona).

STARGARDT, J. I972. The ceramic industry of Southern Thailand in the Srivijayan period (in English and Thai), Archaeology, Journal of Silapakorn University, Bangkok (October), - . 1973a. Southern Thai waterways: archaeological evidence on agriculture shipping and trade in the Srivijayan period, $M a n$, viII (1), 5-29.

$1973 \mathrm{~b}$. Un rapport préliminaire sur la découverte d'un centre industriel de céramique de l'époque çrivijayan dans le sud de la Thaĩlande, Arts Asiatiques, in press.

\section{Earth sciences in archaeology and history}

Professor N. N. Ambraseys of the Engineering Seismology Section of the Department of Civil Engineering, Imperial College of Science and Technology, London, has sent us the following note of warning.

During the last decade there has been a welcome rapprochement between archaeologists, historians and earth scientists. There have been a number of very interesting publications by archaeologists which have considered recent advancements in earth sciences and which have tried, with various degrees of success, to evaluate these developments for archaeology.

Equally important, almost an indispensable tool, is the use of history and archaeology in earthquake prediction studies. Let me explain.

Almost all estimation of seismicity is probabilistic and the probabilities may be computed from observed occurrences of earthquakes. Yet the length of time covered by modern instrumental seismology is negligibly short when compared with the geological time-scale involved in earthquake processes. Thus, in spite of the considerable volume of data for earthquakes in the present century, a much longer period of observation is needed to permit a meaningful statistical treatment. This can be achieved only by resorting to data for earthquakes prior to 1900 and by choosing for study seismic regions where the time-scale is long and the recorded data are good (Ambraseys, 1962, 895; Wilson, 1972, 59).

A systematic study of early earthquakes began in 1960 at this College and it is still in progress. The region selected for study comprises the Eastern Mediterranean Basin which has a very long and well documented history. Already, there have been significant results both of geophysical and historical importance and
I would like to mention three points which have emerged (Ambraseys, 1971, 375).

The first point concerns the interpretation of early earthquakes. Modern man-made structures differ in many respects from old ones and to judge future damage from centuryold case histories can be seriously misleading. For instance, a large distant earthquake fifteen centuries ago would have caused practically no structural damage to Constantinople, Antioch or Nicaea; the same earthquake today would cause damage to a number of modern, more flexible structures in these cities.

The second point concerns the assessment of seismicity of a particular region using extant structures of old age. It is usually considered rather improbable that early structures, liable to damage by earthquakes, could stand for many centuries in seismic regions. The mere fact that quite a few early buildings are still to be found in a state of tolerable preservation in various parts of the world has led to the belief that these places have been free from destructive earthquakes. But our evidence shows that this is not the case. The early buildings that are still standing have, in fact, during their life-time, been subjected to a number of destructive earthquakes and they have survived through a process of natural selection. They are a very small fraction of the total number of structures that existed in early times and they represent today a sample of structures of the best final design and construction, achieved through the ages by trial-and-error techniques or by chance. Thus, the mere fact that a few early monuments are still standing on various sites in Greece, Turkey, Iran or in Syria should not be taken to mean that these sites have been free from damaging earthquakes. 